\title{
HMS: UM SISTEMA ABERTO PARA AUTOMAÇÃO RESIDENCIAL
}

Paulo C.A. Feitosa $\mathrm{Jr}^{1}$, Dalberson Chizzolini Novo ${ }^{1}$, Adilson Direne Atalla ${ }^{1}$, Kleber Manrique Trevisani ${ }^{1}$

${ }^{1}$ Faculdade de Informática de Presidente Prudente - Universidade do Oeste Paulista (UNOESTE). Campus I - CEP 19.050-900 Presidente Prudente - SP - Brazil. \{paulocafjr,dalbao,atalla,kleber\}@unoeste.edu.br

\section{RESUMO}

HMS (House Management System) é um sistema para automação residencial, desenvolvido na plataforma JAVA, que permite controlar aparelhos eletrônicos utilizando uma unidade de controle local ou uma unidade de controle remota, que deve estar conectada por Internet ou rede sem fio. Uma das principais características deste sistema é a facilidade de inserção de aparelhos eletrônicos de tipos diversificados sem precisar realizar mudanças na estrutura do sistema.

Palavras-chaves: automação; java.

\section{HMS: AN OPEN SYSTEM FOR HOME AUTOMATION}

\section{ABSTRACT}

HMS (House Management System) is a system for home automation, developed in JAVA platform, that permits you to control electronic devices using a local control unit or a remote control unit, that must be connected by Internet or wireless network. One of the main characteristics of this system is the easily insertion of diverse kind electronics devices without having to make changes in the structure of the system.

Keywords: Automation;java. 


\section{INTRODUÇÃO}

Nos tempos atuais vem crescendo cada vez mais o uso de computadores para realizar tarefas corriqueiras. Com a popularização dos computadores e a miniaturização dos componentes, tarefas que antes eram impossíveis de serem realizadas computacionalmente devido ao preço elevado do equipamento ou a falta de recursos computacionais, hoje são possíveis. Em algumas situações o usuário nem percebe que está utilizando um recurso computacional.

O computador deixa de ser uma entidade tão evidente para diluir-se no ambiente, mediando atividades do dia-a-dia sem demandar esforço cognitivo para sua utilização. [Bolzani, C. (2004)]

A cerca de 18 anos atrás Mark Weiser denominou de computação ubíqua [Weiser, M (1991)] a existência de sistemas de computadores nos mais triviais objetos que seriam usados de forma que passaria desapercebida do usuário.

"As tecnologias mais profundas são aquelas que desaparecem: são costuradas no tecido da vida cotidiana até ficarem indistinguíveis dela" [Weiser, M (1991)] (Tradução Livre)

Como foi previsto, hoje os sistemas de computadores estão por toda parte. Do cartão de transporte público ao cartão de crédito e também sendo incorporados na automação das residências. Vários dispositivos são criados para facilitar o controle dos aparelhos eletrônicos, pois, o número de aparelhos eletrônicos vem crescendo muito nas residências e controlar todos eles começa ser incomodo e complexo.

A automação residencial proporciona comodidade e diminui trabalhos repetitivos do diaa-dia. Ela também ajuda no controle das tarefas de segurança, como fechar portas e janelas, sendo hoje possível programar um horário para que as janelas fechem ou até mesmo, com ajuda de sensores, que em uma determinada situação elas fechem ou abram sem um comando do usuário.

Este projeto iniciou-se de uma ferramenta denominada MHC (Mobile House Control)
[Bentlin, E. at. al. (2008)] inicialmente criada para controlar aparelhos eletrônicos instalados em uma residência, através de um dispositivo móvel com acesso a internet.

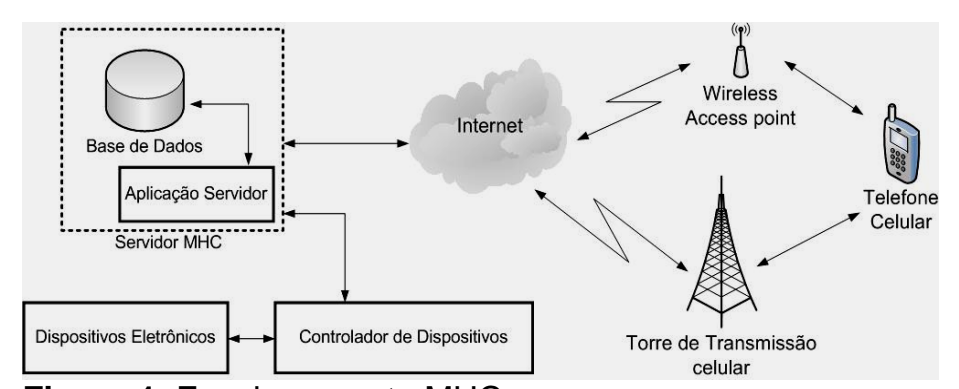

Figura 1. Funcionamento MHC.

A Figura 1 demonstra a arquitetura do MHC onde o telefone celular com o software do $\mathrm{MHC}$ instalado envia comandos para um servidor, que se comunica com o dispositivo a ser controlado.

Nesta arquitetura do $\mathrm{MHC}$, seu único objeto de manipulação era o telefone celular, que conseguia apenas manipular as funções dos aparelhos eletrônicos que já possuíam um cadastrados no sistema. Todos os cadastros que são necessários para o funcionamento do sistema são feitos por SQL, através do SGBD, não existindo um controle de usuário onde permissões diferentes possam ser distribuídas entre eles, e a associação dos aparelhos eletrônicos não é feita de forma visual, mas sim, como os cadastros, através do SQL direto no SGBD.

Para que o MHC pudesse ser utilizado era necessário realizar os devidos aprimoramentos, como uma aplicação com interface para o usuário configurar, cadastrar e manipular o sistema localmente e que essa aplicação proporcionasse todas essas funcionalidades de maneira facilitada para o usuário.

\section{ARQUITETURA DO SISTEMA}

O HMS (House Management System) foi projetado para organizar os componentes do MHC, e desenvolver a parte do sistema que faltava para que ele se tornasse viável. 
Com a nova arquitetura foram adicionados novos componentes, um deles é a interface gráfica que tem por função possibilitar os cadastros necessários para o funcionamento do sistema de forma amigável e sensível ao toque. Esse sistema permite criar usuários e distribuir permissões entre eles, também da possibilidade de associar graficamente um aparelho eletrônico a um local da residência alem de possibilitar a manipulação dos aparelhos eletrônicos localmente.

A arquitetura desse sistema foi planejada para disponibilizar aos fabricantes de aparelhos eletrônicos como (TVs, DVDs, Geladeiras, Lâmpadas, etc..), uma forma simples de desenvolver seus controladores de dispositivos.

Os controladores de dispositivos funcionam como controles remotos de aparelhos como TVs e DVDs, mas ao invés de receberem instruções diretamente da mão do usuário esses controladores recebem as instruções de um servidor instalado na residência. O controlador pode estar embutido dentro do dispositivo ou instalado em um ponto estratégico para comunicação com ele.

O HMS foi definido com intuito de englobar o maior número de dispositivos possíveis, sem que seja necessário ser desenvolvido pelos mantenedores do sistema um controlador de dispositivo para cada um que fosse integrar o sistema. Para isso o HMS foi dividido em quatro componentes, para que os componentes já existentes, possam se comunicar com os controladores de dispositivos desenvolvidos pelos fabricantes.

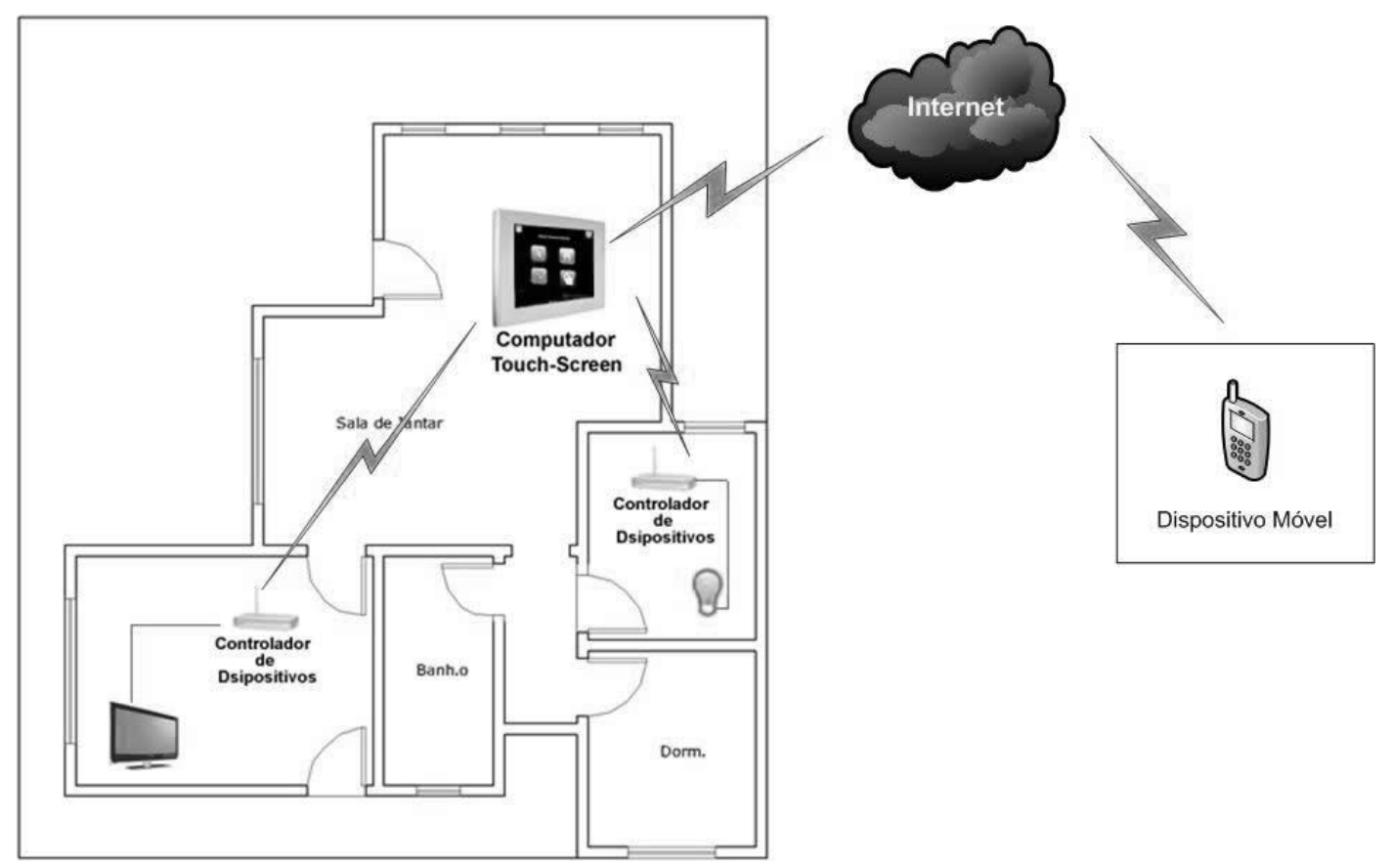

Figura 2. Funcionamento HMS.

A Figura 2 ilustra o funcionamento do HMS de forma geral expondo somente a comunicação entre os componentes do sistema que são; um computador touch-screen, controladores de dispositivos, aparelho celular (dispositivo móvel) e os aparelhos eletrônicos que são a TV e uma lâmpada utilizados no exemplo acima.

O computador touch-screen tem acesso a internet e a rede sem fio do local onde está instalado, e por ser portátil, ele pode ser levado para qualquer lugar da residência, não existindo 
um ponto fixo para seu funcionamento. Através deste computador é possível realizar cadastros de novos usuários e configurar diferentes permissões de manipulação, podendo também importar uma imagem que represente a planta da residência para que os dispositivos sejam associados graficamente aos seus respectivos locais na residência. O usuário ainda pode realizar configurações como nome do banco de dados, porta de comunicação dos componentes do sistema e a geração os certificados digitais, que são responsáveis pela comunicação segura entre o servidor e o celular.

Esse computador touch-screen é o centro das comunicações dos dispositivos do sistema, e fica responsável por receber todas as requisições do sistema e transmiti-las aos controladores, alem de responder se foi possível ou não realizar a operação.

Os controladores de dispositivos comunicam-se com o computador touch-screen e com os dispositivos controlados por eles. Um controlador pode manipular um ou vários dispositivos. Para que a comunicação com computador touch-screen aconteça esse controlador deve respeitar um protocolo de comunicação, que é a única parte do sistema que o fabricante do controlador precisa conhecer, já a manipulação dos dispositivos pode ser realizada da maneira que o fabricante definir e não precisa ser conhecida pelo sistema.

O aparelho celular (dispositivo móvel) pode manipular os dispositivos que estão associados à residência, usando a internet ou a rede wireless da residência.

A manipulação pode ser feita remotamente pelo celular ou na residência através do computador touch-screen. Quando uma manipulação é requisitada pelo celular é enviada uma mensagem para o computador, que retransmite ao controlador responsável pelo dispositivo a ser manipulado. O controlador efetua a operação e responde ao computador qual foi o resultado da operação, e assim o computador envia uma mensagem de notificação ao componente que requisitou a manipulação. Quando a manipulação parte do próprio computador, as mensagens já são enviadas aos controladores de dispositivos e a partir desse ponto seguem os mesmos passos descritos a cima. 


\section{COMPONENTES DO SISTEMA}

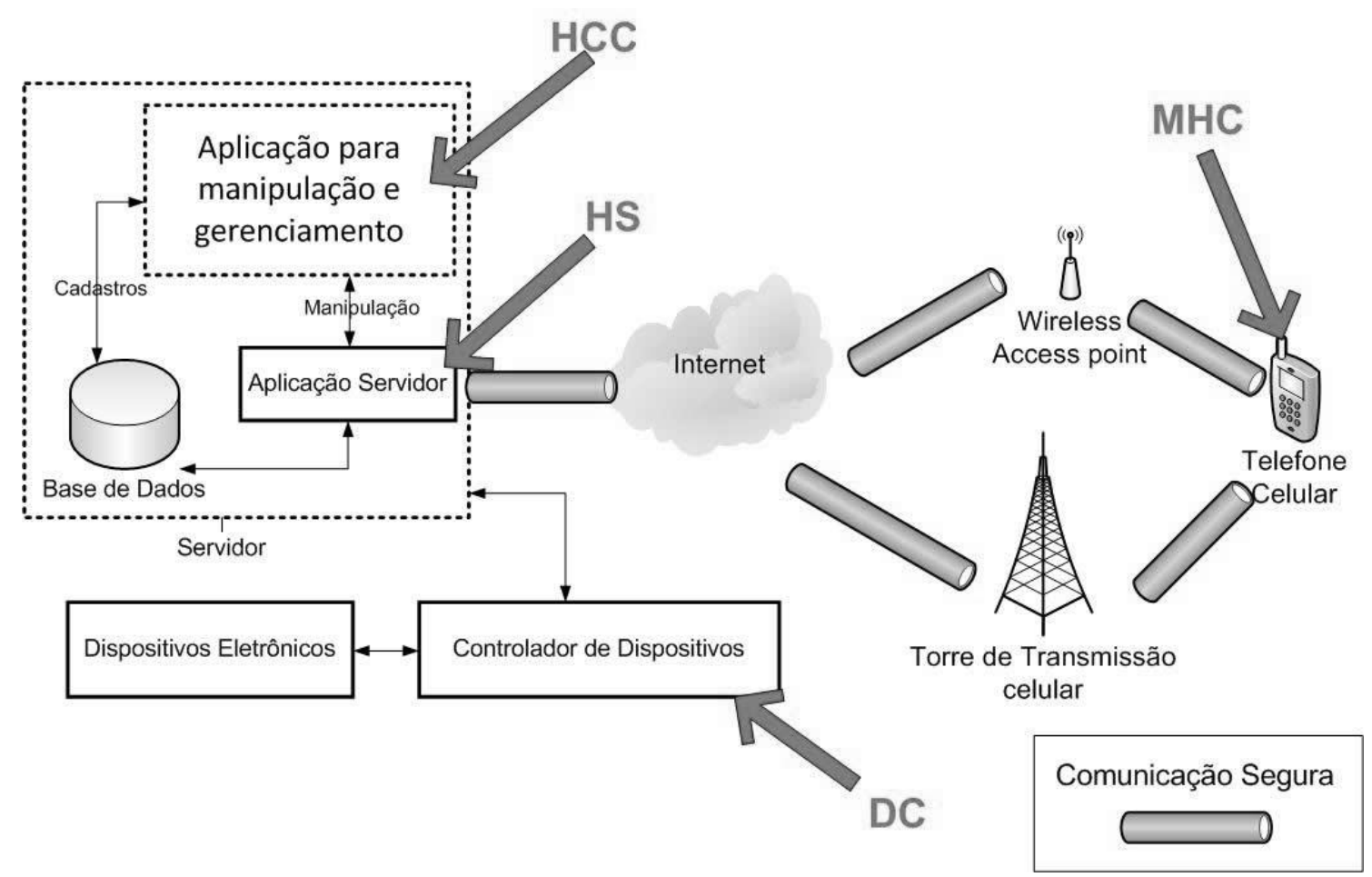

Figura 3. Componentes HMS.

A Figura 3 mostra detalhadamente os vários sistemas que estão instalados nos componentes do HMS, o HCC (House Control Center); HS (House Server); DC (Device Control); MHC (Mobile House Contro). Nesta seção será apresentado de forma mais detalhada cada um dos componentes do sistema HMS.

Todos os componentes criados para $O$ sistema HMS foram desenvolvidos em JAVA, pois ela é uma linguagem de programação estável e como roda em cima de uma máquina virtual, tornando possível o mesmo sistema ser utilizado em várias plataformas como LINUX e no WINDOWS.

\subsection{HS (House Server)}

É o aplicativo servidor de todo o HMS. Todos os outros componentes podem se comunicar com o HS através de mensagens pré-definidas no protocolo de comunicação[Bentlin, E. at. al. (2008)]. O HS é o responsável por realizar todo tipo de manipulação, sendo assim ele recebe requisições do $\mathrm{MHC}$ e do HCC.

Para segurança do sistema existe um protocolo seguro entre o MHC e o HS. Para a comunicação do HCC com HS isto não é necessário, já que estes estão na mesma máquina. $\mathrm{O}$ HS fica responsável pela comunicação com o DC, enviando as mensagens de manipulação que foram recebidas do $\mathrm{HCC}$ ou do MHC. 


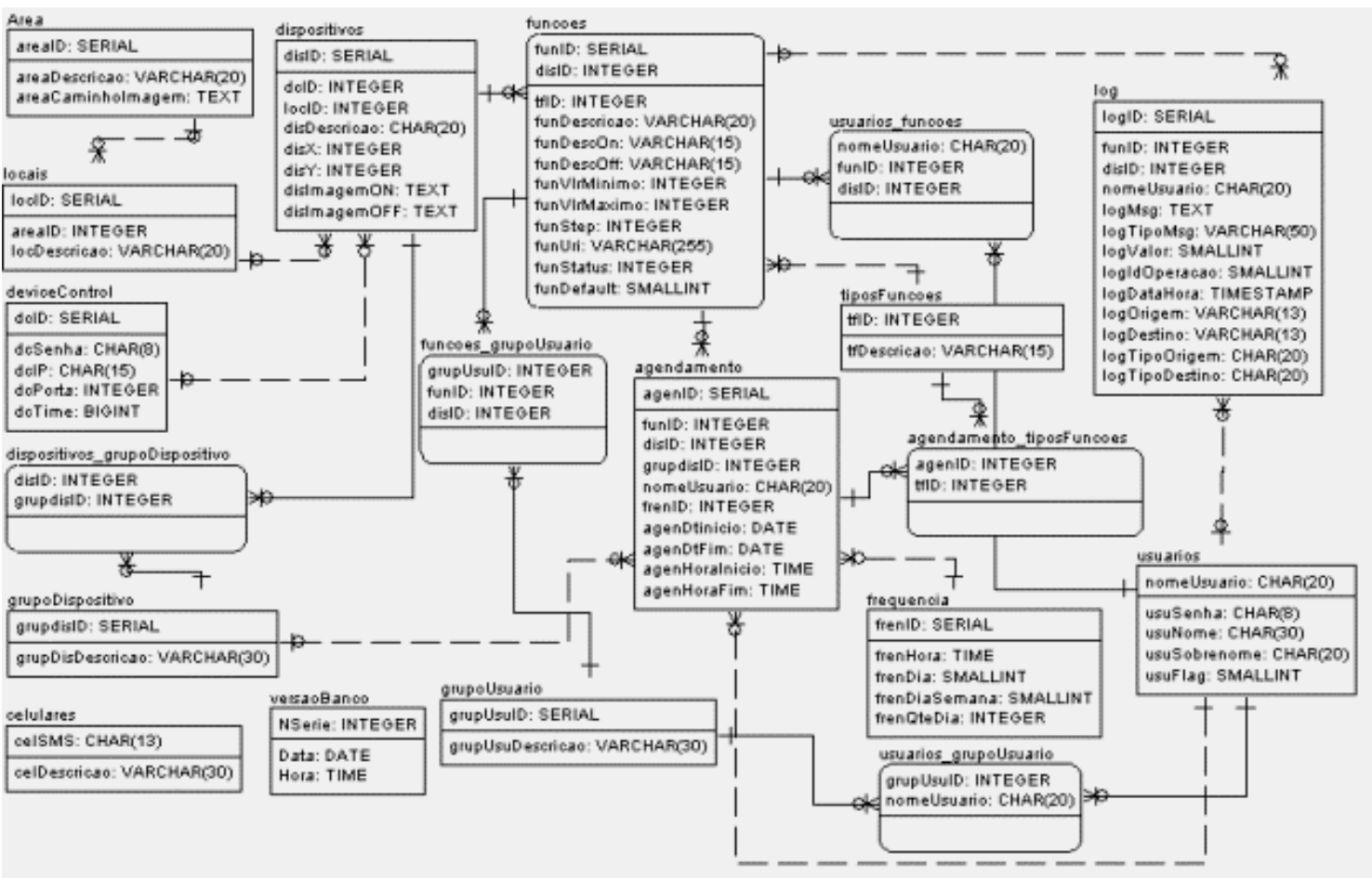

FIGURA 4. MODELO DE BANCO DE DADOS DO HMS.

Para que fosse possível autenticar o celular, foi necessário criar uma identificação que fosse única para cada aparelho. Foram realizadas pesquisas e foi detectado que o número do SMS de cada aparelho seria ideal para ser utilizado com este proposito, já que este numero não se repete e é possível de ser capturado via linha de código. Para tanto foi criado a tabela celulares no banco de dados como apresenta a Figura 4. Para que o usuário possa utilizar o celular para manipular os aparelhos eletrônicos, ele deve fazer o cadastro do numero SMS do celular que é disponibilizado pelo software que é instalado nele para realizar a manipulação MHC, assim quando o usuário for realizar a autenticação do aparelho através de usuário e senha o software mandará o numero de SMS do aparelho e o HS fará a comparação entre o aparelho cadastrado e 0 numero que foi enviado.

Com as tabelas de área, locais, device control, dispositivos e funções, apresentadas na Figura 4 o HS consegue identificar o local que se encontra o aparelho eletrônico, reconhecê-lo e buscar quais funções são possíveis de manipular.

Quando o aparelho celular realiza a autenticação o HS envia a lista de locais, aparelhos e status desses aparelhos. Quando o celular envia a mensagem de manipulação, o HS verifica qual aparelho está sendo requisitado qual - status atual desse aparelho e envia a mensagem ao seu controlador.

Antes de mandar a lista com todos os aparelhos para o celular, o HS tem que verificar quais aparelhos o usuário que se autenticou tem permissão de manipular. Para isso ele se utiliza das tabelas usuário_funcoes e funcoes_grupoUsuario apresentadas na Figura 4.

\subsection{HCC (House Control Center)}

É o aplicativo responsável pelo gerenciamento do HMS e funciona como um ponto de controle no local.

O HCC foi desenvolvido para sanar todos os problemas do antigo MHC referente à parte de 
configuração, gerenciamento e controle, que eram realizados diretamente no banco de dados. Agora com este sistema, é possível realizar o cadastro de novos usuários e grupo de usuários, onde são associados às permissões de manipulação do sistema. Com apoio dessa ferramenta é possível montar uma representação gráfica da residência e associar os aparelhos eletrônicos aos respectivos locais da casa.
Para ser possível montar a representação gráfica da residência, o usuário deve cadastrar uma área e associar uma imagem a ela. Depois de realizar esse cadastro o usuário pode arrastar os aparelhos eletrônicos que estão disponíveis no sistema, selecionando o aparelho e clicando no local da imagem que deseja inserir, como apresentado na Figura 5.

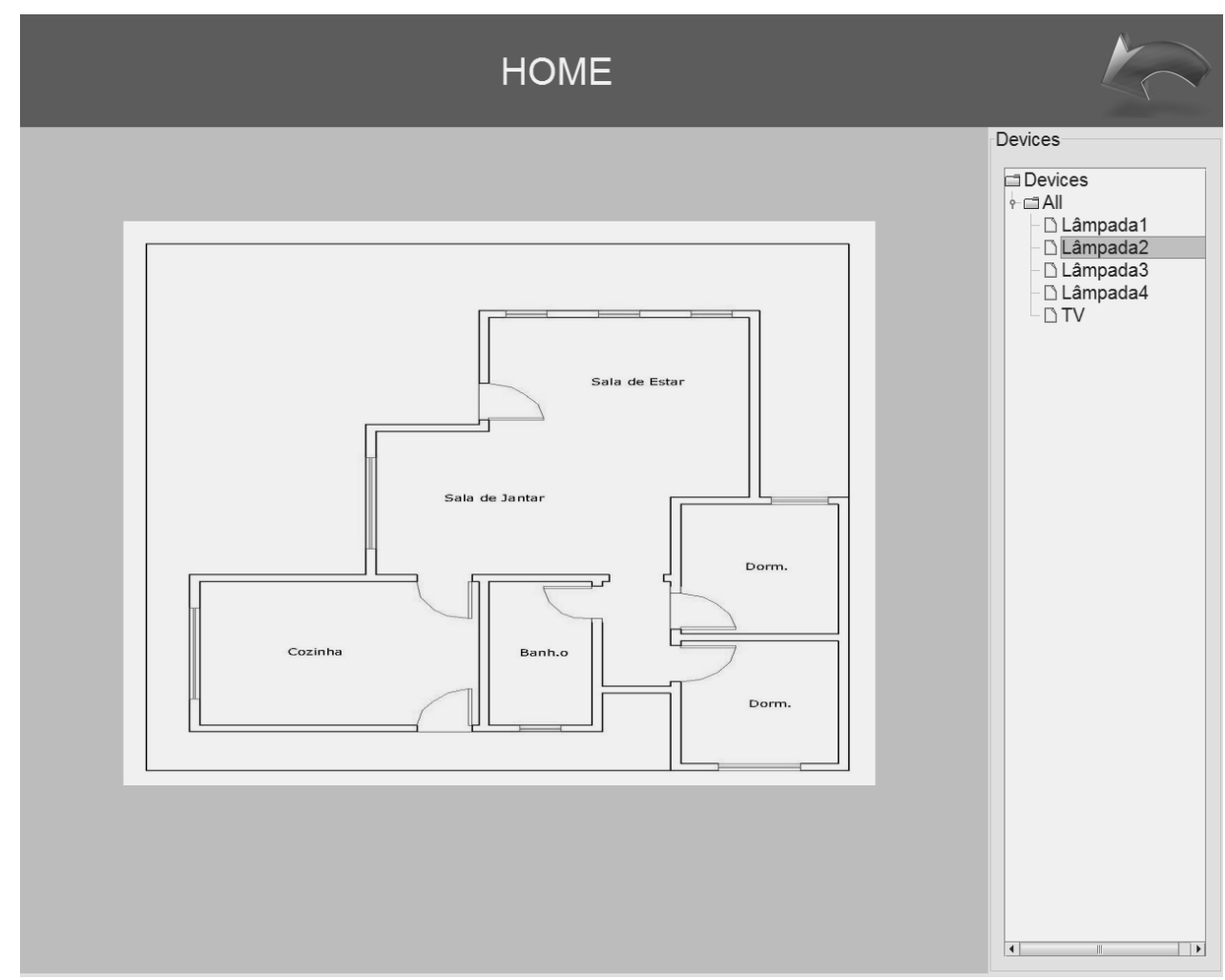

Figura 5. Tela para Representação da Residência e para Manipulação de Dispositivos.

Esta tela apresentada na Figura 5 além de associar os dispositivos aos locais da casa, permite ainda a manipulação deles. Depois de associados eles ficarão disponíveis na tela e com um toque no ícone do aparelho será acionado sua função principal. Quando o aparelho tem mais de uma função é necessário pressionar a tela por 1 segundo, para abrir uma janela onde poderão ser manipuladas todas as funções desse aparelho.

O HMS permite que vários usuário sejam cadastrados e cada um deles tenha permissões diferentes para manipulação dos aparelhos.

O controle de usuário é realizado por grupo de usuários, sendo assim, para que um usuário tenha alguma permissão de manipulação esse usuário deve estar associado a um grupo. Cada aparelho eletrônico registrado no sistema pode ser associado a um ou vários grupos, permitindo assim que dois grupos diferentes manipulem o mesmo aparelho ou que um grupo tenha permissão em um aparelho e o outro não.

Todas as configurações necessárias para o funcionamento do HMS podem ser realizadas utilizando o HCC, por ele é possível configurar o banco de dados, as portas de comunicação dos componentes do HMS e até gerar os certificados digitais necessários para a comunicação segura do HS com o celular. 


\subsection{MHC (Mobile House Control)}

É o aplicativo instalado no celular que pode manipular todos os dispositivos que foram associados no HCC, para poder realizar a manipulação o usuário deve se autenticar no MHC que carregará as funções disponíveis de acordo com a permissão concedida a ele no HCC, todas essas manipulações são enviadas ao HS.

Quando o MHC recebe a lista de locais, aparelhos eletrônicos e funções desses aparelhos, ele monta um menu onde o usuário pode navegar entre os locais ex.(quarto, sala, banheiro) e manipular os aparelhos que ali estão associados, a Figura 6 apresenta as telas que realizam essa operação.
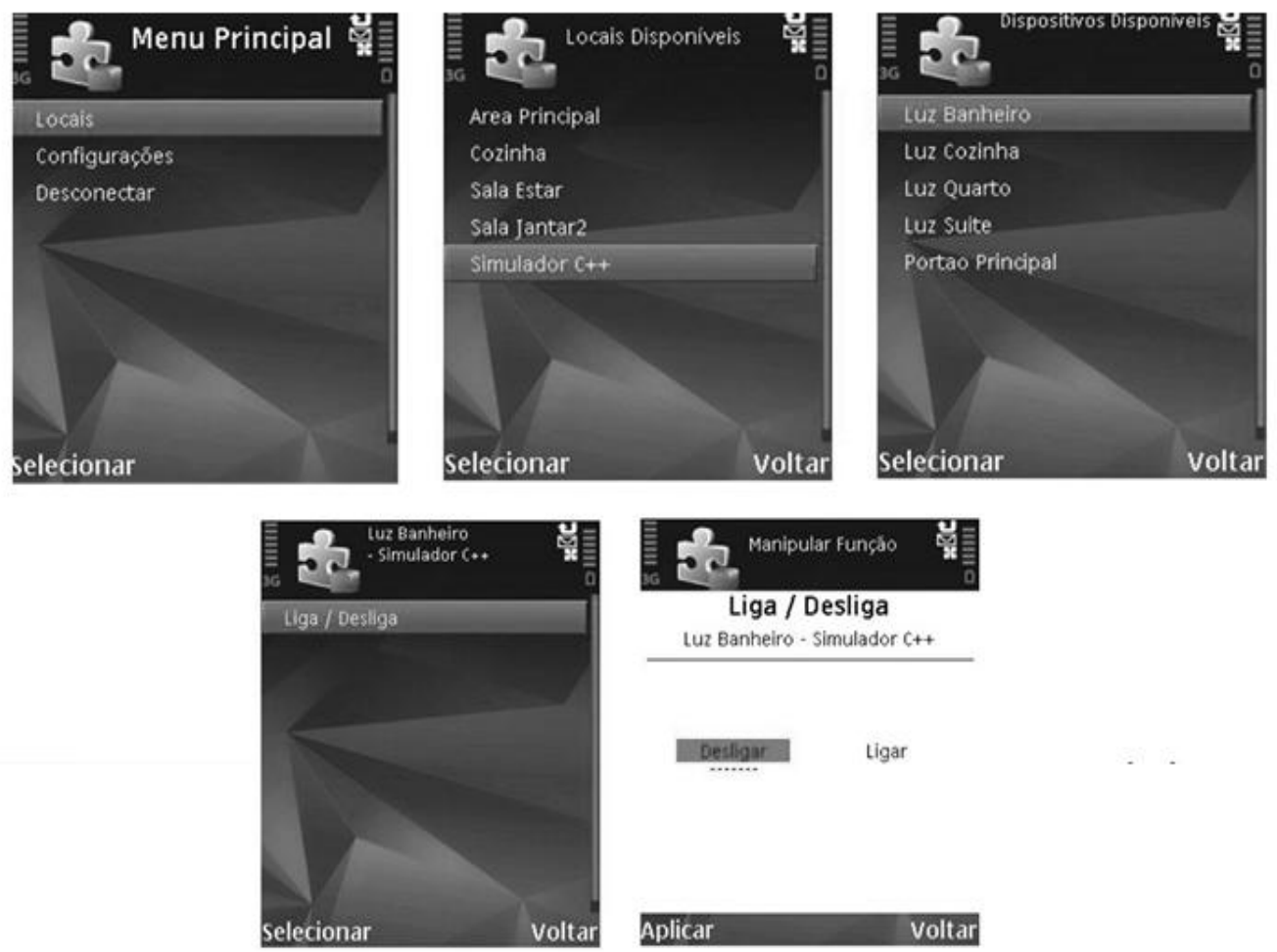

Figura 6. Telas de Movimentação do MHC.

\subsection{DC (Device Controller)}

Este componente é disponibilizado pelo fabricante dos aparelhos eletrônicos e é responsável pela manipulação física dos aparelhos eletrônicos. Ele recebe mensagens de manipulação do $\mathrm{HS}$ e executa da forma que foi programado pelo seu desenvolvedor, depois de manipular ele responde ao HS com o resultado da operação.

Este componente permite que aparelhos diversificados sejam inseridos no HMS sem que seja necessário o desenvolvimento de novos hardwares para cada aparelho eletrônico.

Para testar o HMS foi necessário desenvolver um simulador em software, por não dispormos de um hardware específico.

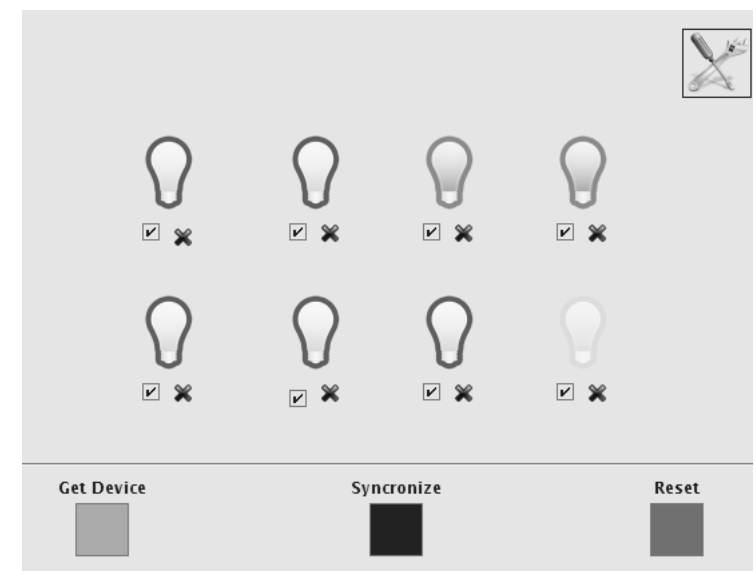

Figura 7. Simulador DC. 
O software desenvolvido, cuja tela principal é ilustrada na Figura 7 , simula 0 gerenciamento de até 8 lâmpadas de dois (Liga/Desliga) ou mais estados (Gradual). Como o hardware do DC deve ser especifico para a função que ele irá desempenhar, foi criado uma interface com 3 botões que através de leds indicam o status da operação. O GetDevice, que quando pressionado inicializa a operação de reconhecimento dos dispositivos conectados ao DC. O Syncronize, que quando pressionado realiza a comunicação com o HS, para efetuar a operação de cadastro do DC e dos dispositivos controlados por ele. O Reset, que quando pressionado realiza a comunicação com o HS para que ele remova o DC e todos os dispositivos controlados por ele.

Utilizando esse software é possível manipular as lâmpadas simulando o uso do interruptor. É possível também desabilitá-las, reproduzindo uma situação em que a lâmpada foi removida do soquete, essa função pode ser realizada desmarcando a caixa de checagem (checkbox) abaixo de cada lâmpada. Outra situação que é possível simular é desvincular o dispositivo do DC, para isso é necessário clicar no ícone $\mathrm{X}$ abaixo da lâmpada.

Algumas configurações devem ser realizadas para $O D C$ conseguir se comunicar com o HS, é necessário que ele conheça os dados pertinentes para comunicação, como IP, senha de acesso e porta. Para isso todo DC deve disponibilizar uma interface de configuração onde esses dados podem ser inseridos.

\section{CONSIDERAÇÕES FINAIS}

Para demonstrar a viabilidade desse sistema foi criado um ambiente de testes, com dois computadores e um celular, um computador representou o servidor do HMS, onde foram instalados o HS e o HCC e o outro computador foi instalado um simulador do DC, citado na seção 3.4. No celular foi instalado o MHC.

Os dois computadores foram conectados por uma rede sem fio e o celular se conectava na mesma rede para poder se comunicar com HS como mostra a Figura 8.

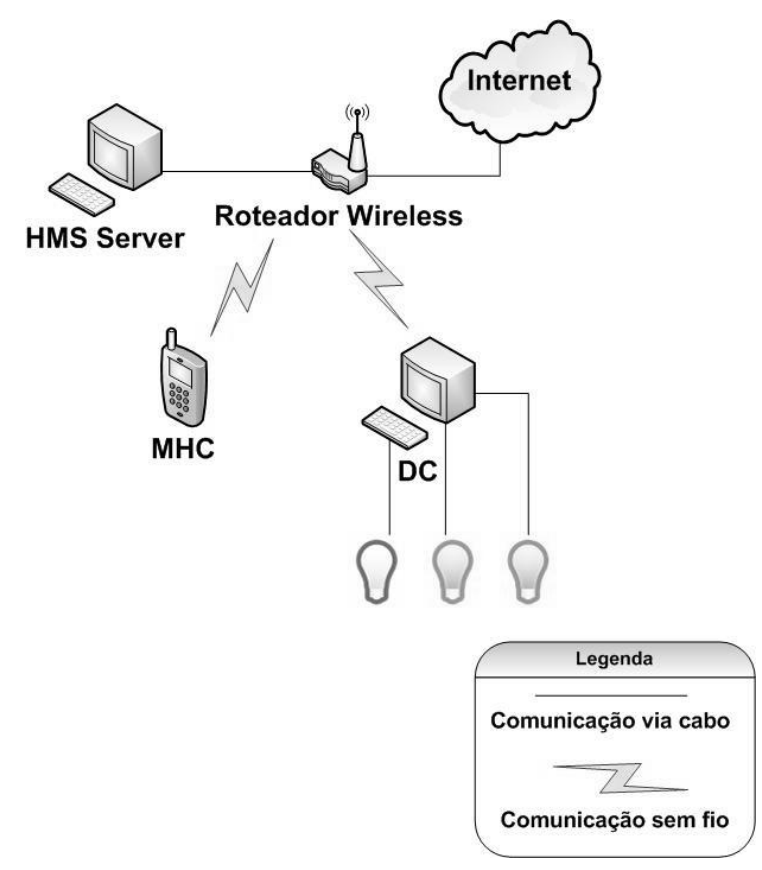

Figura 8. Ambiente de Teste.

Foram realizados vários testes como inserção dos aparelhos eletrônicos no sistema, associação dos aparelhos aos locais e manipulação de dispositivos.

Os resultados foram satisfatórios, pois a comunicação dos dispositivos funcionou como previsto e as funcionalidades propostas no inicio do desenvolvimento foram sanadas.

No decorrer do desenvolvimento foi detectado a necessidade de mais algumas funções:

$\rightarrow$ Visualizador e editor de logs, pois o HS já registra todas suas operações mas ainda não é possível visualizar tais registros.

$\rightarrow$ Uma função de agendamento das manipulações, para permitir o usuário agendar a manipulação de um determinado dispositivo.

$\rightarrow$ Uma funcionalidade onde seja possivel criar eventos, como por exemplo, quando uma determinada lâmpada for acesa uma outra também deve acender.

$\rightarrow$ E para comprovar o funcionamento real de um DC é necessário implementar um 
hardware que realize essa função.

Já existem estudos em andamento para tornar o DC um componente de software ao invés de um hardware como ele foi projetado para ser. Desta forma, ele funcionaria como um plug-in para o HS e realizaria a intermediação entre o HS e os aparelhos eletrônicos. Este projeto visa a redução dos componentes de hardware do HMS, gerando também economia, além de facilitar o desenvolvimento do DC para o fabricante do aparelho eletrônico.

Existe também outro estudo que visa a independência de rede para o HS ele poderá trabalhar com várias redes diferentes ao mesmo tempo um exemplo é poder enviar mensagens tanto no padrão IEEE 802.11 quanto no padrão IEEE 802.15.4.

\section{REFERENCIAS}

BENTLIN, Everton C.; TREVISANI, Kleber M. (2008). MHC: Um sistema para controle de locais utilizando dispositivos móveis. Monografia (Bacharelado em Ciência da Computação) "Unoeste - Universidade do Oeste Paulista", Presidente Prudente.

BOLZANI, Caio A. M. (2004), Residências Inteligentes. São Paulo: Livraria da Física.

$\begin{array}{lll}\text { JDK } & 6 & \text { Documentation. }\end{array}$ http://java.sun.com/javase/6/docs/, Dezembro.

PINHEIRO, M.; SPITZ, R. (2007). O design de interação em ambientes de ubiqüidade computacional. Congresso Internacional de Design da Informação, Curitiba; Anais...CD-ROM. Curitiba.

WEISER, M. (1991), "The computer for the 21st century," Scientific American, vol. 265, no. 3, pp. 66-75. 